\title{
A DFT INVESTIGATION OF A POLYCYCLIC STANNYLENE MODEL; STRUCTURAL CHARACTERIZATION AND STABILITY ASSESSMENT
}

\author{
IONUT-TUDOR MORARUa, GABRIELA NEMES ${ }^{a^{*}}$
}

\begin{abstract}
The first part of this study aims at evaluating by DFT methods the structural features and the stability of a stannylene derivative, Sn(II) being included into an extended polycyclic framework. Natural Bond Orbital (NBO) analyses are performed in order to understand bonding patterns and also the role of secondary electronic effects on the stability of this unsaturated derivative. In the second part, the coordination of NHC and THF ligands to the Sn(II) atom of the polycyclic stannylene species are investigated. The strength of these interactions and the nature of the chemical bonds formed are also discussed.
\end{abstract}

Keywords: stannylene, stilbene, DFT calculations, NBO analyses.

\section{INTRODUCTION}

Metallylenes, the heavier analogues of carbenes, have gained an increased attention in the last period, due to their possible applications in catalysis or as precursors in the synthesis of new polymers with controlled properties.

Starting with the first transient metallylene, these compounds also attracted interest from the fundamental point of view, since they display several contrasting features compared to those of carbenes. Previous studies performed on this class of compounds featured their characteristic electronic configuration involving an inert lone pair (LP) situated in the ns orbital and a vacant $p$ orbital on the $E(\mathrm{Si}, \mathrm{Ge}, \mathrm{Sn})$ atom [1-5]. Therefore, they can in principle act as both Lewis acids and Lewis bases. As a result of their amphoteric properties, metalylenes are highly reactive, short-lived and difficult to characterize, unless stabilization by steric bulk or electron donating groups is achieved. [6-8]

\footnotetext{
a Babeş-Bolyai University, Faculty of Chemistry and Chemical Engineering, 11 Arany Janos str., RO-400028, Cluj-Napoca, Romania

*Corresponding author: gabriela.nemes@ubbcluj.ro
} 
The singlet-triplet energy differences for $\mathrm{H}_{2} \mathrm{E}$ species $(\mathrm{E}=\mathrm{C}, \mathrm{Si}, \mathrm{Ge}$, $\mathrm{Sn}, \mathrm{Pb}$ ) were previously evaluated by ab-initio calculations. For all heavier analogues, the singlet state is more stable, with calculated gaps of $16.7 \mathrm{kcal} / \mathrm{mol}$ for silylene, $21.8 \mathrm{kcal} / \mathrm{mol}$ for germylene, $24.8 \mathrm{kcal} / \mathrm{mol}$ for stanylene and $34.8 \mathrm{kcal} / \mathrm{mol}$ for plumbylene, while in the case of $\mathrm{H}_{2} \mathrm{C}$ : carbene, the singlettriplet energy difference was estimated as $-14.0 \mathrm{kcal} / \mathrm{mol}$. [9] The same study additionally emphasizes that the relative stabilities of the singlet species $\mathrm{R}_{2} \mathrm{E}$ : $(\mathrm{E}=\mathrm{C}, \mathrm{Si}, \mathrm{Ge}, \mathrm{Sn}, \mathrm{Pb} ; \mathrm{R}=$ alkyl or aryl), related to their corresponding dimers, $\mathrm{R}_{2} \mathrm{E}=\mathrm{ER}_{2}$, increases in the series: $\mathrm{C}<\mathrm{Si}<\mathrm{Ge}<\mathrm{Sn}<\mathrm{Pb}$.

Stabilization of metallylenes can be achieved either thermodynamically and/or kinetically. More precisely, kinetic stabilization can be accomplished by introduction of bulky substituents onto the molecule which can block the highly reactive vacant $p$ orbital, while thermodynamic stabilization can be achieved by coordination to different organic, organometallic or inorganic fragments [10,11].

If the steric hindrance is insufficient, the metallylene will be subjected to self-oligomerization, leading to the corresponding dimer or even polymers. [3]

Starting with the first completely characterized tin(II) derivative stabilized by the tridentate 2,6-bis[(dimethylamino)methyl]phenyl group reported by van Koten in 1989 [12], a new topic, that of pincer ligand stabilized metallylenes, was implemented. The majority of the pincer ligands reported in literature as being used for stabilizing metalylenes consist in N,C,N-pincer type ligands [1317] while only few examples of O,C,O-pincer ones were successfully reported until now. [18-21]

Since the synthesis of the first $\mathrm{N}$-heterocyclic carbene, 1,3-di-1adamantyl-imidazol-2-ylidene, noted as NHC throughout the text [22], these species were intensively used in stabilization of metalylenes due to their electronic proprieties, namely the strong $\mathrm{N} \rightarrow \mathrm{C}$ (carbene) m-donation. [23] Other carbenes used as stabilizing co-ligand of metallylenes are benzimidazole [24] or acyclic derivatives [25], but the Arduengo type imidazole-based carbenes are much widely used due to their enhanced stability. While NHC-germylenes have numerous examples reported to date [26-29], their reactivity is less investigated, in opposing trends to those of $\mathrm{NHC}$-silylene analogues, for which fewer examples are known. [30-32]. In the case of NHC-stabilized stannylenes, only few examples were reported in the literature [33,34], their reactivity being less investigated because of their low stability in solution.

In order to increase the thermodynamic and kinetic stabilization of metallylenes, the phosphaalkenyl Mes ${ }^{*} \mathrm{P}=\mathrm{C}<$ unit was connected to the NHCgermylene and $\mathrm{NHC}$-stanylene derivatives [35, 36]. It is known that in the case of low coordinate species containing a heavy element of groups 14 and 15 , with the Mes ${ }^{*} \mathrm{P}=\mathrm{C}-\mathrm{E}$ skeleton, the phosphaalkenyl moiety induces a stabilizing effect [37-40]. The newly stable phosphaalkenyl metalylenes were completely characterized and their reactivity was investigated [41-43]. 
A DFT INVESTIGATION OF A POLYCYCLIC STANNYLENE MODEL; STRUCTURAL CHARACTERIZATION AND STABILITY ASSESSMENT

In order to increase the stability of the heavier analogues of carbene, we have focused our recent research towards systems in which the germanium(II) or the tin(II) atom is included into a cycle, with prospects of aromaticity or pseudo-aromaticity. Based on our previous studies [44-46], we consider that the fluorenyl-metallylenes or metallapine derivatives (containing a stilbene group) will be thermodynamically stabilized due to electronic effects induced by extending the conjugation on the heterorganic cycle.

In this work we report a computational chemistry study concerning structural characterization and stability assessment of a polycyclic stannylene (the structure is shown in Figure 1, being further noted as I). In addition, possible formation of adducts between I and the NHC and THF ligands was also assessed.

\section{RESULTS AND DISCUSSION}

The structural features of a stannylene-pine derivative I are investigated by DFT calculations. The B3LYP hybrid functional and its long range dispersion corrected form, B3LYP-D3, are employed within this study in order to assess whether dispersion corrections influence the computed data.

The optimized molecular structures of I, performed with both B3LYP and B3LYP-D3 functionals, are shown in Figure 1. The flanking fused phenyl rings and the seven membered tin-containing heterocycle are quasi-planar in the molecular geometry obtained with the B3LYP functional, a calculated value of about $177.5^{\circ}$ being obtained for the C3-C1-C2-C4 dihedral (see Figure 1a and Table 1). On the other hand, the calculation performed with B3LYP-D3 functional reveal a bent molecular structure minimum, the lateral phenyl groups being displaced cis with respect to the central stannepin ring. Nevertheless, both structures depicted in Figure 1 display similar distances for the Sn-C chemical bonds (in-between 2.18 and $2.19 \AA$ ), while for the C-Sn-C bonding angle, calculated values are close to $100^{\circ}$ in both cases (see Table 1 ).

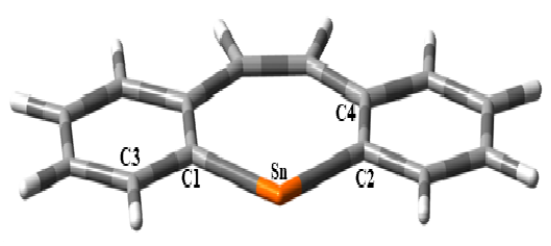

a.

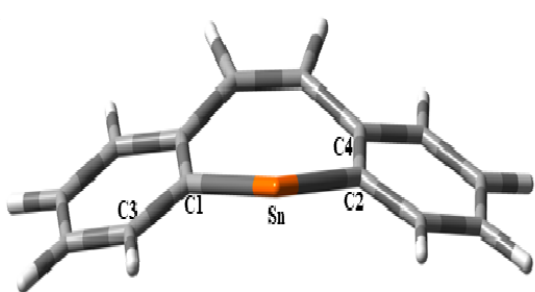

b.

Figure 1. Molecular structures of stannylene I optimized at (a) B3LYP/Def2-TZVP and (b) B3LYP-D3/Def2-TZVP levels of theory. 
Energy differences between the planar and the angular geometries of I are calculated with both B3LYP and B3LYP-D3 functionals. As in both cases the results are roughly identical in terms of calculated bond lengths and bonding angles, we appreciate that the planar structure achieved at the B3LYP level of theory represents a good approximation for a merely singlepoint energy calculation with B3LYP-D3 functional (without any geometry optimization), in order to determine the magnitude of the planar-angular gap (bending potential) of I at B3LYP-D3 level. A similar procedure is also accomplished for the B3LYP functional. Calculated energy gaps between planar and bent structures exhibit low values in both cases $(0.1 \mathrm{kcal} / \mathrm{mol}$ at both B3LYP and B3LYP-D3 levels), underlining the ability of the Sn atom towards flipping between the two sides of the stilbene moiety.

Table 1. Selected geometrical parameters for stannylene I

\begin{tabular}{|c|c|c|}
\hline Parameter & B3LYP & B3LYP-D3 \\
\hline Sn-C1 $(\AA)$ & 2.181 & 2.185 \\
\hline Sn-C2 $(\AA)$ & 2.181 & 2.185 \\
\hline C1-Sn-C2 $\left(^{\circ}\right)$ & 102.8 & 100.1 \\
\hline C3-C1-C2-C4 $\left(^{\circ}\right)$ & 177.4 & 156.0 \\
\hline
\end{tabular}

*The atom labeling for tabulated parameters is in agreement with the one illustrated in Figure 1.

Natural Bond Orbital (NBO) calculations reveal weak stabilization effects occurring from the stilbene moiety towards the vacant $p$ orbital on the Sn atom. Figure 2 depicts the NB orbitals involved in these charge transfer interactions. The overall stabilization energy, consisting in two electronic departures of the type $\pi(\mathrm{C}-\mathrm{C}) \rightarrow p(\mathrm{Sn})$ for each of the investigated species illustrated in Figure 2, has calculated values of $12.5 \mathrm{kcal} / \mathrm{mol}$ in the case of planar geometry (B3LYP) and of $15.9 \mathrm{kcal} / \mathrm{mol}$ for the angular one (B3LYP-D3).

Data presented throughout this study relies on calculations performed on the singlet state of stannylene I. In agreement with previous studies, the NBO analyses performed on I displays a mainly $s$ character $(82 \% s, 18 \% p)$ for the LP on the $\mathrm{Sn}$ atom. Nevertheless, the singlet-triplet gap $\left(\Delta \mathrm{E}_{\mathrm{ST}}\right)$ is also evaluated. For both functionals the singlet state of $I$ is considerably more stable than the triplet one. Calculated $\Delta \mathrm{E}_{\mathrm{ST}}$ amounts are of $37.2 \mathrm{kcal} / \mathrm{mol}$ (B3LYP) and respectively $37.3 \mathrm{kcal} / \mathrm{mol}$ (B3LYP-D3), zero-point energy corrections (ZPE) being included in the energetic comparisons. However, these values are with about $12.5 \mathrm{kcal} / \mathrm{mol}$ higher than previous ab-initio data reported for $\mathrm{H}_{2} \mathrm{Sn}$ [9]. The enhanced stabilization of the singlet state for the cyclic stannylene I, compared to $\mathrm{H}_{2} \mathrm{Sn}$, can be understood in terms of $\pi(\mathrm{C}-\mathrm{C}) \rightarrow p(\mathrm{Sn})$ 
A DFT INVESTIGATION OF A POLYCYCLIC STANNYLENE MODEL; STRUCTURAL CHARACTERIZATION AND STABILITY ASSESSMENT

secondary electronic effects (Figure 2). The increase in $\Delta \mathrm{E}_{\mathrm{ST}}$ for the cyclic species is in line with the calculated amount of the stabilization energy corresponding to the donor-acceptor interactions $(12.5-15.9 \mathrm{kcal} / \mathrm{mol}$, see the NBO section above).

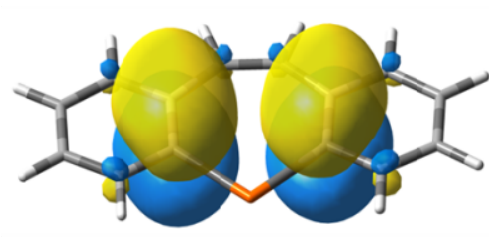

a1.

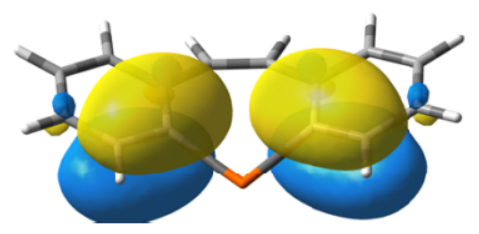

b1.

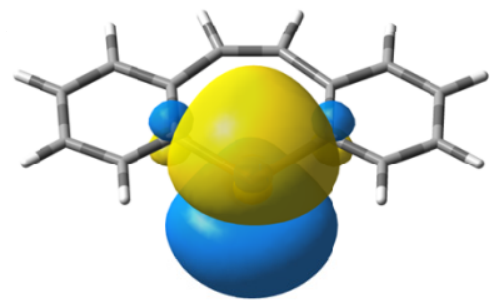

a2.

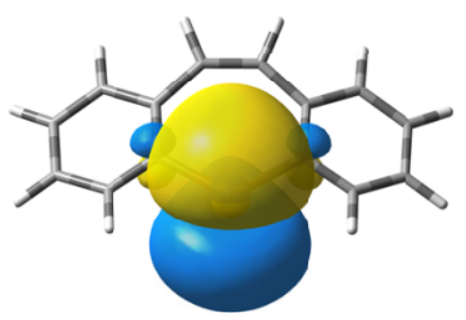

b2.

Figure 2. NB orbitals involved in charge transfer interactions in I for calculations performed at B3LYP/Def2-TZVP (a1 and a2) and B3LYP-D3/Def2-TZVP (b1 and b2) DFT levels of theory. a1) $\pi(\mathrm{C}-\mathrm{C})$ donor NBOs on the planar structure; a2) $p(\mathrm{Sn})$ acceptor NBO for planar geometry; b1) $\pi(\mathrm{C}-\mathrm{C})$ donor NBOs on the angular structure; b2) $p(\mathrm{Sn})$ acceptor NBO for bent geometry.

Another key aspect to be taken into account when questioning stability of targeted derivatives consists in the assessment of the HOMOLUMO gap. [47] Large gaps indicate enhanced stabilization, highlighting thus considerable energy separation between the ground and the first excited state. In the case of I, calculated HOMO-LUMO separation has values of $3.33 \mathrm{eV}(76.8 \mathrm{kcal})$ at B3LYP level and of $3.27 \mathrm{eV}(75.3 \mathrm{kcal})$ at B3LYP-D3. In order to gain relevant comparisons, the HOMO-LUMO gap for the NHC carbene is additionally calculated at the same levels of theory, $\mathrm{NHC}$ serving as a well know example of stable unsaturated species.

The calculated HOMO-LUMO separation for NHC is of $6.18 \mathrm{eV}$ (142.7 kcal) at both B3LYP and B3LYP-D3 levels, value that is noticeably higher than those computed for $\mathrm{I}$. 
Figure 3 illustrates the frontier MOs computed for I with both functionals. In both cases, HOMO is predominantly located on the stilbene moiety, with small contributions from the $\mathrm{Sn}$ atom. Within the angular structure, the contribution of the $\mathrm{Sn}$ atom to HOMO is noticeably higher than in the case of the planar geometry. Regarding LUMO, it is located to a large extent on the Sn atom for both planar and angular structures, and consists in a vacant $p$ orbital.

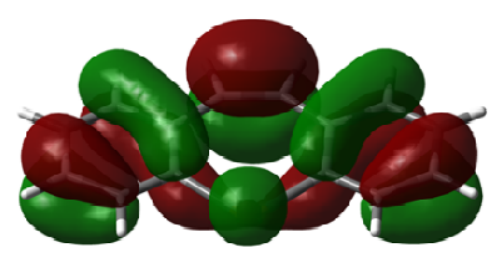

a.

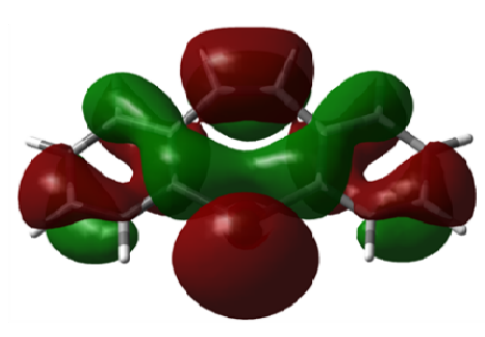

c.

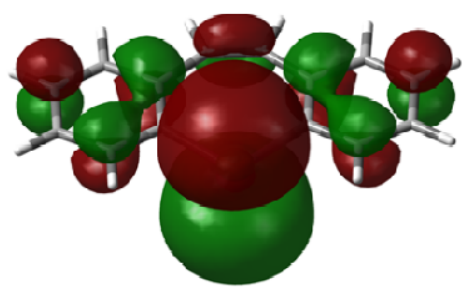

b.

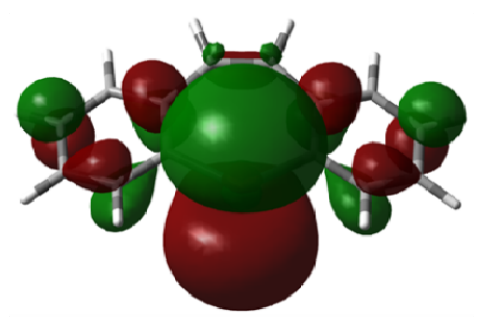

d.

Figure 3. Frontier MOs calculated for I: a) HOMO for planar structure (B3LYP/ Def2-TZVP); b) LUMO for planar molecule (B3LYP/Def2-TZVP); c) HOMO for bent geometry (B3LYP-D3/Def2-TZVP); d) LUMO for angular structure (B3LYPD3/Def2-TZVP).

\section{Stabilization of stannylene I with NHC and THF ligands}

Blocking the unoccupied $p$ orbital of metallylenes with strong Lewis bases represents one of the know reactions used to stabilize these species. Owing to the notoriety of the $\mathrm{NHC}$ carbene towards stabilizing unsaturated derivatives by enhanced electron donation, intermediates of the type I-NHC (Figure 4) were considered within this DFT study. 


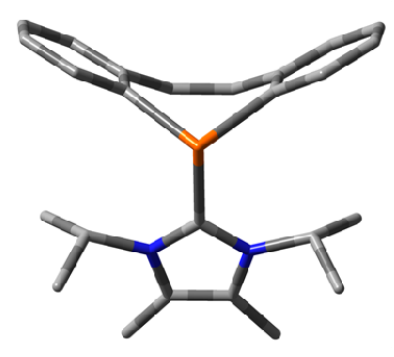

a.

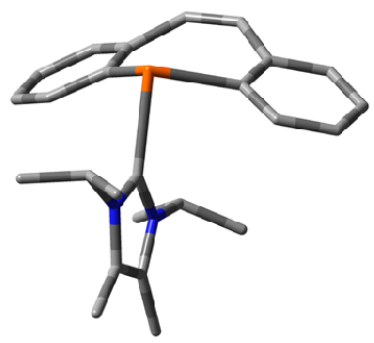

b.

Figure 4. Molecular geometries of I-NHC species for: a) isomer la-NHC, the NHC species and the flanking phenyl rings are oriented in trans; b) isomer lb-NHC, the NHC group and the lateral phenyl rings are disposed in cis; hydrogen atoms were omitted for clarity reasons.

In addition, the molecular geometries of I-THF adducts (Figure 5) were computed. The reason behind choosing THF as another possible stabilizing ligand was of interest for the actual work because (i) THF represents a widely used solvent in organometallic chemistry and thus it is worth knowing its stabilizing effects on metallylenes, and also (ii) for gaining a broader overview on the bonding pattern in cyclic stannyllenes.

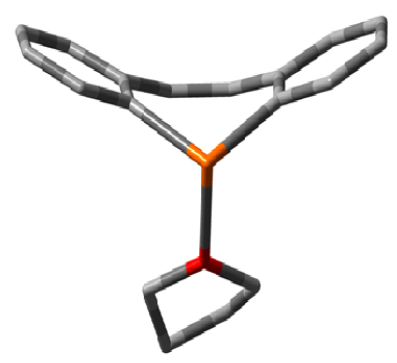

a.

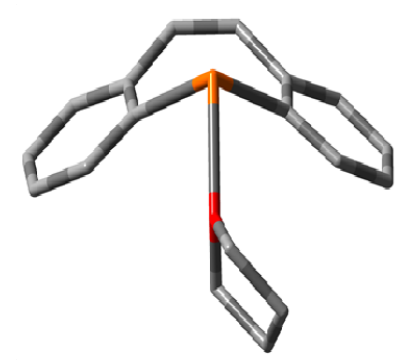

b.

Figure 5. Molecular structures of I-THF species for: a) isomer la-THF, the THF ligand and the phenyl rings are oriented in trans with respect to the central heterocyle; $\mathbf{b}$ ) isomer $\mathbf{I b}$-THF, the THF ligand and the phenyl groups are oriented in cis with respect to the central heterocyle; hydrogen atoms were omitted for enhanced clarity.

For both I-NHC and I-THF species, two different isomers are considered for each case: one isomer in which the flanking phenyl groups of the polycyclic stannyllene and the NHC/THF ligands are disposed in trans, and another one in which they are oriented in cis (see Figures 4 and 5). The molecular structures delivered by both B3LYP and B3LYP-D3 functionals are very similar 
for each of the I-NHC and I-THF adducts. Therefore, only one set of structures (one cis and one trans isomer) are illustrated in each of the cases, and not two different ones as was in the case of I, for which the two employed functionals lead to two different geometries.

The calculated energy differences between the investigated isomers are small (ZPE included), with the trans isomer being the most stable one in all cases. For instance, for I-NHC species, calculated gaps are of $1.6 \mathrm{kcal} / \mathrm{mol}$ at B3LYP level and of $1.7 \mathrm{kcal} / \mathrm{mol}$ for the dispersion corrected functional, B3LYP-D3. In the case of I-THF, calculated cis-trans energy differences are of $0.7 \mathrm{kcal} / \mathrm{mol}$ for B3LYP and of $1.3 \mathrm{kcal} / \mathrm{mol}$ for B3LYP-D3.

Table 2 presents some key structural parameters calculated for I-NHC and I-THF adducts. As it can be noticed, the values computed with B3LYP are slightly higher than those computed with B3LYP-D3. Nevertheless, differences are negligible for the chemical bonds, their lengths being found to be the same within $1 / 1000 \AA$ for the Sn-C bonds, and within $1 / 100 \AA$ in the case of $\mathrm{Sn} \leftarrow \mathrm{C}$ and $\mathrm{Sn} \leftarrow \mathrm{O}$ coordinate bonds. Angles differ between B3LYP and B3LYP-D3 by at most $0.6^{\circ}$ in the case of I-NHC, and by at most $1.2^{\circ}$ for I-THF. In comparison with stannylene I, Sn-C bonds formed with the flanking phenyl groups are slightly elongated upon coordination of $\mathrm{NHC}$ (up to $0.054 \AA$ at B3LYP level and to $0.052 \AA$ at B3LYP-D3) and of THF (up to $0.037 \AA$ at $B 3 L Y P$ level and to $0.035 \AA$ at B3LYP-D3). A decrease of the C-Sn-C angle is also noticed in all cases (see Tables 1 and 2 for comparisons).

Table 2. Selected geometrical parameters for the calculated systems I-NHC and I-THF

\begin{tabular}{|c|c|c|c|c|c|c|c|c|c|}
\hline \multirow{2}{*}{ I-NHC } & \multicolumn{2}{|c|}{ B3LYP } & \multicolumn{2}{|c|}{ B3LYP-D3 } & \multirow{2}{*}{ I-THF } & \multicolumn{2}{|c|}{ B3LYP } & \multicolumn{2}{|c|}{ B3LYP-D3 } \\
\hline & trans & cis & trans & cis & & trans & cis & trans & cis \\
\hline $\mathrm{Sn} \leftarrow \mathrm{C}(\mathrm{NHC})(\AA)$ & 2.398 & 2.418 & 2.387 & 2.403 & $S n \leftarrow O(T H F)(\AA)$ & 2.438 & 2.434 & 2.424 & 2.420 \\
\hline Sn-C $(\AA)$ & 2.235 & 2.228 & 2.237 & 2.231 & $\mathrm{Sn}-\mathrm{C}(\AA)$ & 2.210 & 2.218 & 2.212 & 2.220 \\
\hline C-Sn-C $\left({ }^{\circ}\right)$ & 92.9 & 97.4 & 92.3 & 97.6 & C-Sn-C $\left(^{\circ}\right)$ & 97.0 & 94.4 & 95.9 & 92.2 \\
\hline
\end{tabular}

An energetic index for the $\mathrm{Sn} \leftarrow \mathrm{C}(\mathrm{NHC})$ and $\mathrm{Sn} \leftarrow \mathrm{O}$ (THF) bonds, based on the second order perturbation analysis of the NBO technique, is presented in Table 3. Note that the second order perturbation energy for the $\mathrm{Sn} \leftarrow \mathrm{C}(\mathrm{NHC})$ bonding is not available in the case of the trans isomer of I-NHC (see Table 3), being regarded by the NBO analyses as rather covalent, and not as a "classical" donor-acceptor interaction usually displayed in the output of the NBO calculations. However, the contribution of Sn to the Sn $\leftarrow \mathrm{C}$ bond is small: $\sim 18 \%$ in the case of both B3LYP and B3LYP-D3. According to the computed data, the strength of $S n \leftarrow C$ bonding is far higher 
A DFT INVESTIGATION OF A POLYCYCLIC STANNYLENE MODEL; STRUCTURAL CHARACTERIZATION AND STABILITY ASSESSMENT

than that of $\mathrm{Sn} \leftarrow \mathrm{O}$ bonds. However, these trends are in line with previous DFT studies concerning the stabilization of posphaalkenyl germylenes with various Lewis bases ( $\left.\mathrm{NHC}, \mathrm{THF}, \mathrm{Et}_{2} \mathrm{O}\right)$ [42].

Table 3. NBO data for $\mathrm{Sn} \leftarrow \mathrm{C}(\mathrm{NHC})$ and $\mathrm{Sn} \leftarrow \mathrm{O}$ (THF) chemical bonds of I-NHC and I-THF adducts

\begin{tabular}{|c|c|c|c|c|}
\hline \multirow{2}{*}{ Coordinative Bond } & \multicolumn{2}{|c|}{ B3LYP } & \multicolumn{2}{|c|}{ B3LYP-D3 } \\
\hline & trans & cis & trans & cis \\
\hline $\mathrm{Sn} \leftarrow \mathrm{C}(\mathrm{NHC})\left(\mathrm{kcal} \mathrm{mol}^{-1}\right)$ & - & 117.2 & - & 120.0 \\
\hline $\mathrm{Sn} \leftarrow \mathrm{O}(\mathrm{THF})\left(\mathrm{kcal} \mathrm{mol}^{-1}\right)$ & 30.3 & 30.4 & 30.5 & 31.0 \\
\hline
\end{tabular}

For the I-THF type adducts, NBO calculations also suggest the occurrence of weak intermolecular hyperconjugative interactions of the type $p(\mathrm{O}) \rightarrow \sigma^{*}(\mathrm{Sn}-\mathrm{C})$. The calculated energies of these effects range in-between 3.7 and $4.4 \mathrm{kcal} / \mathrm{mol}$. Nonetheless, these kinds of hyperconjugative effects were shown to play important roles in molecular stannoxanes [48].

\section{CONCLUSIONS}

The structural features and the stability of a stannylene-pine type I species were investigated using DFT calculations. NBO analyses revealed that the extended cyclic framework of investigated stannylene assures an increased stabilization compared to acyclic counterparts, due to charge transfer interactions of the type $\pi(\mathrm{C}-\mathrm{C}) \rightarrow p(\mathrm{Sn})$. The enhanced stability is reflected in the singlet-triplet gap which in terms is considerably higher than the one previously reported for $\mathrm{H}_{2} \mathrm{Sn}$ species. Concerning the calculated HOMOLUMO gap, DFT data revealed a separation of about $3.3 \mathrm{eV}$, which is significantly lower than the one calculated for the reference $\mathrm{NHC}$ species, which had a gap of $6.2 \mathrm{eV}$. Further stabilization can be achieved via coordination, the role of $\mathrm{NHC}$ and THF ligands being assessed in this respect. The strength of $\mathrm{Sn} \leftarrow \mathrm{C}(\mathrm{NHC})$ interaction is significantly higher than that of $\mathrm{Sn} \leftarrow \mathrm{O}$ (THF) bond, in line with previous DFT studies on germylenes. Nevertheless, the stabilization with THF is undoubtable, being at the same time of great practical importance, since THF serves as a widely used solvent in metallylene chemistry.

Finally, the present study compared the geometries delivered by B3LYP with its dispersion corrected form, B3LYP-D3. According to the DFT data, a good agreement of both bond length and angles was achieved among the two employed functionals, highlighting thus that the effect of the D3 long-range dispersion corrections on the computed data is negligible in the present case. 


\section{EXPERIMENTAL SECTION}

\section{Computational Details}

Density Functional Theory (DFT) calculations were performed with the Gaussian 09 software package [49]. Geometries were fully optimized in the gas phase without any symmetry constraints, employing the B3LYP [50] hydrid functional and also its dispersion corrected form, B3LYP-D3 (with D3 standing for Grimme's dispersion corrections [51]), and the valance triplezeta Def2-TZVP basis set [52]. Stuttgart effective core potentials (ECPs) were used for computing the relativistic core electrons of the $\mathrm{Sn}$ atom. The ECPs are included in the implementation of the basis set in Gaussian 09. The optimization criteria were set to tight in all cases. Vibrational frequencies were computed in order to characterize the nature of the stationary points, and also used for calculating zero-point energy corrections (ZPE). According to the vibrational analyses, all optimized geometries correspond to minima. For all calculations, the integration grid used was of 99 radial shells and 950 angular points for each shell $(99,950)$, precisely the "ultrafine" grid within Gaussian 09. Natural Bond Orbital (NBO) [53] single-point calculations were carried out on the optimized molecular structures, in order to shed light on the structural features and on the nature of the chemical bonding in the analyzed species. The Gaussian 09 implemented version of the NBO program was used.

\section{ACKNOWLEDGMENTS}

This work was supported by a grant of Ministery of Research and Innovation, CNCS-UEFISCDI, project number PN-III-P4-ID-PCE-2016-0351, within PNCDI III.

\section{REFERENCES}

1. W. P. Neumann, Chem. Rev., 1991, 91, 311-334.

2. J. Barrau; G. Rima, Coord. Chem. Rev., 1998, 178-180, 593-622.

3. Y. Mizuhata; T. Sasamori; N. Tokitoh, Chem. Rev., 2009, 109, 3479-3511.

4. F. Lollmahomed; L. A. Huck; C. A. Harrington; S. S. Chitnis; W. J. Leigh, Organometallics, 2009, 28, 1484-1494.

5. P. A. Rupar; V. N. Staroverov; K. M. Baines, Science, 2008, 322, 1360-1363.

6. S. Nagendran; H. W. Roesky, Organometallics, 2008, 27, 457-492.

7. S. K. Mandal; H. W. Roesky, Chem. Commun., 2010, 6016-6041.

8. M. Asay; C. Jones; M. Driess, Chem. Rev., 2011, 111, 354-396.

9. G. J. Trinquier, Am. Chem. Soc., 1990, 112, 2130-2131.

10. P. P. Power, Chem. Rev., 1999, 99, 3463-3504.

11. J. Barrau; J. Escudié; J. Satgé, Chem. Rev., 1990, 90, 283-319.

12. J. T. B. H. Jastrzebski; P. A. Van der Schaaf; J. Boersma; G. Van Koten; M. C. Zoutberg; D. Heijdenrijk, Organometallics, 1989, 8, 1373-1375. 
A DFT INVESTIGATION OF A POLYCYCLIC STANNYLENE MODEL; STRUCTURAL CHARACTERIZATION AND STABILITY ASSESSMENT

13. M. P. Bigwood; P. J. Corvan; J. J. Zuckerman, J. Am. Chem. Soc., 1981, 103, 76437646.

14. C. Bibal; S. Mazières; H. Gornitzka; C. Couret, Angew. Chem. Int. Ed., 2001, 40, 952-954

15. S.-P. Chia; H.-X. Yeong; C.-W. So, Inorg. Chem., 2012, 51, 1002-1010.

16. S. Khan; P. P. Samuel; R. Michel; J. M. Dieterich; R. A. Mata; J.-P. Demers; A. Lange; H. W. Roesky; D. Stalke, Chem. Commun., 2012, 48, 4890-4892.

17. B. Kašná; R. Jambor; M. Schürman; K. Jurkschat, J. Organomet. Chem., 2008, 693, 3446-3450.

18. M. El Ezzi; R. Lenk; D. Madec; J.-M. Sotiropoulos; S. Mallet-Ladeira; A. Castel, Angew. Chem. Int. Ed., 2015, 127, 819-822.

19. N. Deak; P. M. Petrar; S. Mallet-Ladeira; L. Silaghi-Dumitrescu; G. Nemeş; D. Madec, Chem. - Eur. J., 2016, 22, 1349-1354.

20. N. Deak; O. Thillaye du Boullay; I.-T. Moraru; S. Mallet-Ladeira; D. Madec; G. Nemes, Dalton Trans., 2019, 48, 2399-2406.

21. N. Deak; I.-T. Moraru; N. Saffon-Merceron; D. Madec; G. Nemes, Eur. J. Inorg. Chem., 2017, 36, 4214-4220.

22. A. J. Arduengo; R. L. Harlow; M. Kline, J. Am. Chem. Soc., 1991, 113, 361-363.

23. D. Nemcsok; K. Wichmann; G. Frenking, Organometallics, 2004, 23, 3640 3646.

24. F. E. Hahn; L.Wittenbecher; R. Boese; D. Bläser, Chem. Eur. J. 1999, 5, 1931-1935.

25. R. W. Alder; P. R. Allen; M. Murray; A. G. Orpen, Angew. Chem. Int. Ed. Engl., 1996, 35, 1121-1122.

26. A. J. Arduengo; R. H. V. Dias; J. C. Calabrese; F. Davidson, Inorg. Chem., 1993, 32, 1541-1542.

27. A. Sidiropoulos; C. Jones; A. Stasch; S. Klein; G. Frenking, Angew. Chem. Int. Ed., 2009, 48, 9701-9704.

28. P. A. Rupar; V. N. Staroverov; K. M. Baines, Organometallics, 2010, 29, 4871-4881.

29. A. C. Filippou; O. Chernov; B. Blom; K. W. Stumpf; G. Schnakenburg, Chem. Eur. J., 2010, 16, 2866-2872.

30. R. S. Ghadwal; H. W. Roesky; S. Merkel; J. Henn; D. Stalke, Angew. Chem. Int. Ed., 2009, 48, 5683-5686.

31. A. C. Filippou; O. Chernov; G. Schnakenburg, Chem. Eur. J., 2011, 17, 13574 13583.

32. H. Cui; C. Cui, Dalton Trans., 2011, 40, 11937-11940.

33. K. C. Thimer; I. S. M. Al-Rafia; M. J. Ferguson; R. McDonald; E. Rivard, Chem. Commun., 2009, 7119-7121.

34. B. Bantu; G. M. Pawar; U. Decker; K. Wurst; A. M. Schmidt; M. R. Buchmeiser, Chem. Eur. J., 2009, 15, 3103-3109.

35. D. Matioszek; T.-G. Kocsor; A. Castel; G. Nemes; J. Escudié; N. Saffon, Chem. Commun., 2012, 48, 3629-3631.

36. T.-G. Kocsor; G. Nemes; N.Saffon; S. Mallet-Ladeira; D. Mandec; A. Castel; J. Escudié, Dalton Trans., 2014, 43, 2718-2721.

37. P. M. Petrar; R. Septelean; H. Gornitska; G. Nemes, J. Organomet. Chem., 2015, 787, 14-18.

38. R. Septelean; G. Nemes; J. Escudié; I. Silaghi-Dumitrescu; H. Ranaivonjatovo; P. M. Petrar; H. Gornitzka; L. Silaghi-Dumitrescu; N. Saffon, Eur. J. Inorg. Chem., 2009, 628-634. 
39. R. Septelean; H. Ranaivonjatovo; G. Nemes; J. Escudié; I. Silaghi-Dumitrescu; H. Gornitzka; L. Silaghi-Dumitrescu; S. Massou, Eur. J. Inorg. Chem., 2006, 4237-4241.

40. G. Cretiu Nemes; H. Ranaivonjatovo; J. Escudié; I. Silaghi-Dumitrescu; L. SilaghiDumitrescu; H. Gornitzka; Eur. J. Inorg. Chem., 2005, 1109-1113.

41. T.-G. Kocsor; D. Matioszek; G. Nemes; A. Castel; J. Escudié; P. Petrar; N. Saffon-Merceron; I. Haiduc, Inorg. Chem., 2012, 51, 7782-7787.

42. T.-G. Kocsor; P. Petrar; G. Nemeş; A. Castel; J. Escudié; N. Deak; L. SilaghiDumitrescu; Comput. Theor. Chem., 2011, 974, 117-121.

43. R. Septelean, I.-T. Moraru; T. Kocsor; N. Deak; N. Saffon; A. Castel; G. Nemes, Inorg. Chim. Acta, 2018, 475, 112-119.

44. L. Buta; R. Septelean; I.-T. Moraru; A. Soran; L. Silaghi-Dumitrescu; G. Nemes, Inorg. Chim. Acta, 2019, 486, 648-653.

45. P. M. Petrar; R. Septelean; H. Gornitska; G. Nemes, J. Organomet. Chem., 2015, 787, 14-18.

46. G. Cretiu Nemes; L. Silaghi-Dumitrescu; I. Silaghi-Dumitrescu; J. Escudié; H. Ranaivonjatovo; K. C. Molloy; M. F. Mahon; J. Zukerman-Schpector, Organometallics, 2005, 24, 1134-1144.

47. R. Hoffmann; P. v. R. Schleyer; H. F. Schaefer, Angew. Chem. Int. Ed., 2008, $47,7164-7167$.

48. I.-T. Moraru; P. M. Petrar; G. Nemes, J. Phys. Chem. A, 2017, 121, 2515-2522.

49. M. J. Frisch, G. W. Trucks, H. B. Schlegel, G. E. Scuseria, M. A. Robb, J. R. Cheeseman, G. Scalmani, V. Barone, G. A. Petersson, H. Nakatsuji, X. Li, M. Caricato, A. Marenich, J. Bloino, B. G. Janesko, R. Gomperts, B. Mennucci, H. P. Hratchian, J. V. Ortiz, A. F. Izmaylov, J. L. Sonnenberg, D. Williams-Young, F. Ding, F. Lipparini, F. Egidi, J. Goings, B. Peng, A. Petrone, T. Henderson, D. Ranasinghe, V. G. Zakrzewski, J. Gao, N. Rega, G. Zheng, W. Liang, M. Hada, M. Ehara, K. Toyota, R. Fukuda, J. Hasegawa, M. Ishida, T. Nakajima, Y. Honda, O. Kitao, H. Nakai, T. Vreven, K. Throssell, J. A. Montgomery, Jr., J. E. Peralta, F. Ogliaro, M. Bearpark, J. J. Heyd, E. Brothers, K. N. Kudin, V. N. Staroverov, T. Keith, R. Kobayashi, J. Normand, K. Raghavachari, A. Rendell, J. C. Burant, S. S. Iyengar, J. Tomasi, M. Cossi, J. M. Millam, M. Klene, C. Adamo, R. Cammi, J. W. Ochterski, R. L. Martin, K. Morokuma, O. Farkas, J. B. Foresman, D. J. Fox, Gaussian 09, revision E.01; Gaussian, Inc.: Wallingford, CT, 2009.

50. a) C. Lee, W. Yang, R. G. Parr. Phys. Rev. B: Condens. Matter Mater. Phys. 1988, 37, 785. b) A. D. Becke. J. Chem. Phys. 1993, 98, 5648-5652.

51. S. Grimme, J. Antony, S. Ehrlich, H. Krieg. J. Chem. Phys. 2010, 132, 154104.

52. a) A. Schafer, C. Huber, R. Ahlrichs, J. Chem. Phys. 1994, 100, 5829; b) D. Rappoport, F. Furche. J. Chem. Phys. 2010, 133, 134105.

53. a) F. Weinhold, C. R. Landis, Valency and Bonding: A Natural Bond Orbital Donor-Acceptor Perspective; Cambridge Univ. Press: Cambridge, U.K., 2005. b) F. Weinhold, C. R. Landis, Discovering Chemistry with Natural Bond Orbitals; Wiley-Interscience: Hoboken, NJ., 2012. c) F. Weinhold, C. R. Landis, E. G. Glendening, Int. Rev. Phys. Chem. 2016, 35, 399 